\title{
Turismo en Uyuni (Bolivia): reconversión, migraciones y pauperización comunitaria, 1996-2013
}

Recibido: 07/02/17 - Aceptado: 19/04/17

\author{
Damir Galaz-Mandakovic* \\ Universidad Católica del Norte, Chile
}

\section{RESUMEN}

Se analiza el proceso de reconversión turística que experimentó la ciudad de Uyuni (Bolivia) después de vivir el desmantelamiento de una estructura laboral tradicional en la década de 1990. Se caracterizan los distintos procesos derivados del turismo, entre ellos los migratorios rurales y urbanos, analizando también la externalidad negativa de las actividades turísticas como la desintegración y pauperización comunitaria como resultado de estructuras capitalistas y neocoloniales que derivaron en la configuración de una nueva jerarquización socioeconómica.

Palabras clave: Uyuni, turismo, pobreza, migraciones, desigualdad económica.

*Correo electrónico: damirgalaz@gmail.com 


\title{
Tourism in Uyuni (Bolivia): reconversion, migration and impoverished community, 1996-2013
}

Recieved: 07/02/17 - Accepted: 19/04/17

\author{
Damir Galaz-Mandakovic* \\ Universidad Católica del Norte, Chile
}

\begin{abstract}
We analyze the conversion process of tourism experienced by the city of Uyuni (Bolivia) after the dismantling of a traditional labor structure in the 1990s. The different processes derived from tourism are characterized, including both rural and urban migration processes. Also, we analyze the negative externality of tourism activities such as disintegration and impoverished community as a result of capitalist and neocolonial structures that lead to the configuration of a new socioeconomic hierarchy.
\end{abstract}

KEY words: Uyuni, tourism, poverty, migrations, economic inequality.

*E-mail: damirgalaz@gmail.com 


\section{Introducción}

Uyuni, en Bolivia, posee el salar más grande del mundo, con una extensión de más de $12000 \mathrm{~km}^{2}$ a una altura de $3653 \mathrm{msnm}$, y alrededor de 32 islas con ecosistemas singulares, además de una serie de paisajes, pueblos, lagunas, rocas, cementerios arqueológicos, volcanes y miradores altiplánicos, todo lo cual ha generado una atracción turística relevante y una correlativa fama mundial que ha sido clave para el sostén de la economía del sudoeste boliviano en las últimas dos décadas.

Según datos recogidos en el archivo de la Dirección Municipal de Turismo y Cultura de Uyuni (2009), en el año 2000 se contabilizó la presencia de 26066 turistas; por su parte, en 2009, el registro indicó 81 223. Estos datos dan cuenta del aumento vertiginoso de visitantes que, en el caso de los años citados, evidencia la triplicación de los flujos de turistas. En el nivel nacional, en 2007 se vio un crecimiento de $9.9 \%$ respecto a 2006; uno similar se produjo en 2010, con un incremento de $8.99 \%$, sumando un total de 731590 viajeros extranjeros (Viceministerio de Turismo, 2011). El 3 de enero de 2013 el diario La Razón indicó: "Bolivia recibió un millón de turistas extranjeros en 2012. El principal destino visitado el año pasado fue el Salar de Uyuni”. El lago Titicaca pasó, según el citado diario, a un segundo lugar.

No obstante, estos procesos de fama internacional han traído aparejados otros procesos sociales que remiten a los desarrollos asimétricos de la reconversión en este tipo de consumos visuales y recreativos, inaugurándose, además, una serie de procesos migratorios tanto de población nacional como internacional en el marco de una aporía y asimetría de estas formas de capitalismo que induce el turismo: el empobrecimiento y subdesarrollo comunitario. Parafraseando a William Roseberry (2002), podemos decir que el turismo es resultado de un proyecto neoliberal que adquiere una inflexión local, insertando relaciones de clase y alianzas regionales y locales, dando espacio a campos de fuerzas complejos, multiasociados y cambiantes, pero también a fuertes desintegraciones, estructurando una dura asimetría entre los pobladores y los agentes del mercado turístico de Uyuni.

En ese sentido, podemos indicar que el turismo en Uyuni conformó un tramado en particular que ha derivado en el usufructo de un bien natural pero que se transcribe como propiedad privada, constituyéndose la naturaleza en un medio comercializable al lucrar y generar acumulación gracias a ella. 
El provecho capitalista del medio natural y sus adyacencias culturales se encuentran principalmente configurados por relaciones empresariales vinculadas con las actividades de inversión y obtención de beneficios, así como relaciones laborales tanto autónomas como asalariadas subordinadas a fines mercantiles (Sombart, 1984; Weber, 1998; Marx, 2004) y turísticos.

En ese escenario capitalista, las empresas foráneas en Uyuni elaboran productos y rutas visuales de etno- y ecoturismo como bienes y servicios en forma privada, existiendo, por extensión, una división del trabajo utilitario para las promociones de los sitios, pero las ganancias las obtienen entidades privadas e individualistas, con lo que se manifiesta una situación contraria al reparto comunitario que se esperaría de un tipo de actividad como el turismo (Sombart, 1984), en la cual participan las mismas comunidades indígenas.

De este modo, se va constituyendo una dependencia hacia un mercado consumista de lo visual, donde no se ejercen relaciones libres de intercambio y comercio, siendo los agentes turísticos los buscadores de beneficios (Lajugie, 1987). Según los designios de ese mercado que consume imágenes y experiencias prístinas del mundo andino, se ejerce la acción sobre el territorio.

Para Schumpeter (1942), el capitalismo es un proceso continuo de innovación tecnológica y "destrucción creativa" impulsado inicialmente por empresarios individuales que buscan beneficios de largo plazo; en ese sentido, en Uyuni, con la ayuda de distintas tecnologías digitales, se innovó en la reproducción y difusión de contenidos especiales para atraer y satisfacer al turista, con narraciones sobre las maravillas del "paisaje más surrealista del planeta”, como lo definió el diario El País de España (22 de noviembre de 2012). Asimismo, el turismo en Uyuni remite a la búsqueda de la satisfacción del turista que llega interesado en temas geológicos, particularidades geográficas, aspectos de la botánica, arte rupestre, arqueología, temáticas antropológicas, étnicas, históricas, pero todo dentro de un marco que destaca la belleza del altiplano, donde los relatos de lo "místico", lo exótico, lo "prístino" y lo "único" marcan la pauta de los contenidos de las distintas agencias de promoción del salar y sus zonas contiguas.

El turismo como derivación del capitalismo significó para Uyuni una trama de innovación que incluyó articulaciones y movimientos que en el transcurso de la diacronía regional se articuló y expandió, por tal razón, "buscar el origen histórico del movimiento en cuestión” (Mandel, 1976, p. 87) resulta fundamental para emprender nuestra crítica. 
Nuestros enfoques para caracterizar y examinar estos procesos se remiten hacia una antropología histórica (Dube, 2007), con el análisis de las dinámicas del devenir etnosocial en Uyuni, considerando las tensiones económicas, sociales, políticas y culturales en tradiciones y contenidos históricos enfrentados por las nuevas formas de colonización, la modernidad y la globalización.

Por tanto, nuestra metodología se sustentó en un trabajo de campo que consistió en desarrollar diversas etnografías en el espacio urbano y rural. Fue realizado entre enero y febrero de 2013 en el poblado de Uyuni, así como también en el propio salar y distintas aldeas colindantes, donde pudimos llevar a cabo una serie de observaciones y entrevistas semiestructuradas a diferentes actores sociales, políticos y comerciales.

Al incluir variados testimonios, estamos incorporando la subjetividad, que se expresó desde el testimonio y la memoria, representándose una situación de convergencia de planos de realidad que nos ayudó a analizar el recorte de la observación del fenómeno para dar cuenta de su condición producente. Con esta incorporación, que contiene al sujeto como parte de su propio discurso y proceso de construcción de conocimiento, fue pertinente recuperarlo desde sus facultades: emocionales e imaginarios, con su intuición, sus contradicciones y quejas; recuperación que posee un carácter de integridad (Zemelman, 2005).

Como se verá en el presente texto, se trabaja con el testimonio, con lo vivido, pero también con lo secundario, con los remanentes de acontecimientos, con todo lo que remita a un archivo. En ese aspecto, se articula la sincronía en la diacronía, relacionando ciertas estructuras con las anécdotas y memorias del testigo (Derrida, 1997). Elzbieta Sklodowska nos dice que el testimonio aporta a ir desintegrando la noción de centro, así como también la de "orden, jerarquía, y se inicia un novísimo trabajo sobre los márgenes, las fronteras, las periferias, las 'minorías': lo periférico pasa a ser observado centralmente” (1992, p. 88).

Nuestros soportes historiográficos se remitieron a la extensa revisión de archivos documentales de servicios públicos y de archivos hemerográficos.

El texto se organiza desde la caracterización del periodo preturístico, a mediados de la década de 1990, hacia su devenir de fama y aumento de visitantes, hasta los tres primeros lustros del siglo xxi, centrándose el análisis en la caracterización de la pauperización comunitaria. 


\section{La era preturística: desmantelamientos y desplazamientos}

El turismo en Uyuni ha significado una reconversión casi totalizante en la economía local y regional. En otro trabajo hemos caracterizado y analizado los procesos referidos al desarrollo del turismo y su conexión con diversos procesos sociológicos y antropológicos derivados de la economía neoliberal que facilita el consumo visual en el marco de una "razón artesanal”, exotización, enfoques eurocéntricos y esencialistas que contribuyen a una etnicidad estática, a la martirización y glorificación de la historia en cuanto relato elaborado a partir de los moldeamientos que induce el turismo (Galaz-Mandakovic, 2014).

Esta reconversión en la economía de Uyuni surgió después de la desestructuración local que propició el primer gobierno del presidente Gonzalo Sánchez de Lozada (1993-1997), quien promovió un amplio y polémico programa de reformas económicas en el que destacaba la privatización de empresas públicas, entre ellas la Empresa Nacional de Ferrocarriles (Enfe). La ciudad de Uyuni resultó ser la ciudad más afectada por la privatización y por el desmantelamiento de maestranzas y distintos talleres mecánicos (López Pérez, 2011).

El diario La Patria de Oruro señaló:

Uyuni sufrió el peor embate por la supresión de fuentes de empleo, puesto que en torno a la empresa giraba la economía de esta gélida tierra. Su maestranza ferroviaria otorgaba importante número de fuentes de trabajo y la circulación de los trenes al sur y viceversa daban origen a una actividad informal que también contribuía a la economía regional [12 de julio de 2011].

Como consecuencia de la capitalización de los ferrocarriles dispuesta por la Ley No 1544 del 21 de marzo de 1994, la Enfe dejó de ser operativa y de prestar servicio ferroviario público, y quedó solo como entidad administradora de los bienes patrimoniales.

Estas decisiones por parte del Poder Ejecutivo de Bolivia trajeron para Uyuni un fuerte impacto demográfico. Alberto André Guamán, exalcalde de la ciudad en varios periodos, afirma que el proceso de desarme dela maestranza tuvo razones técnicas, pero también políticas: la idea era, supuestamente, descentralizar la fuerza de los movimientos de izquierdas en la zona, que se manifestaba a través del sindicalismo ferroviario. Cualquier protesta en Uyuni paralizaba los tránsitos ferroviarios en todo el país, con fuerte impacto en el comercio y la 
producción. El exalcalde comenta: "el gobierno tenía que velar por los intereses y compromisos económicos de las empresas porque estaba en juego la estabilidad del país y sus abastecimientos" (entrevista a Alberto André Guamán, exalcalde y residente de Uyuni, comerciante, febrero de 2013).

Nuestros informantes indican que los sindicatos estaban compuestos generalmente por indígenas o "gente del campo" del "área dispersa de Uyuni”. Muchos de ellos fueron caracterizados por parte de la empresa ferroviaria como "problemáticos", "conflictivos", "perjudiciales” para el "buen funcionamiento de la ciudad”. Entonces, los más perjudicados fueron los trabajadores, muchos de los cuales tuvieron que regresar al campo (entrevistas a Froilán Mamani, jubilado y taxista, residente de Uyuni, y a Alberto André Guamán, febrero de 2013).

Uno de los argumentos clave a la hora de privatizar la empresa ferroviaria estuvo centrado en la supuesta crisis que llevaba arrastrando la compañía. Este último dato es refutado por Ramón Claure, quien entrega, a través del diario $L a$ Razón, las siguientes cifras: "en 1992 movilizaron 869 mil pasajeros y 1.4 millones de toneladas de carga local e internacional [...] Enfe, no estaba en crisis” (12 de marzo de 2009).

La desvinculación laboral de miles trabajadores fue el "trago más amargo" para los uyunenses, nos comentó Manuel Mamani Condori (entrevista realizada en febrero de 2013), quien agrega: "Había más de 1000 trabajadores... hoy [2013] no más de 100”. Alberto André añade: "la compañía había perdido vigencia porque había material más moderno de reparaciones. Se quedó peligrando el pueblo al cerrar la maestranza...”. Nuestro entrevistado denuncia que él, ejerciendo como alcalde de Uyuni en un tercer periodo (1996-1997), fue testigo del incumplimiento de los compromisos llevados por el Estado para con los trabajadores:

Al privatizar les han ofrecido a los mineros $\$ 1000$ bolivianos por año de trabajo. En cambio a los ferroviarios les han ofrecido $\$ 3$ bolivianos por año. ¡Entonces era una locura la diferencia! [...] Yo era alcalde cuando se estaba viviendo este proceso, yo les decía a los trabajadores que no se fueran porque el pueblo se iba a quedar vacío. Ellos me decían: "pero qué quiere que hagamos, con la plata del desahucio me compro una casa afuera, en otra ciudad y hago mi vida”... Entonces, muchos se fueron... 
De este modo comenzó un éxodo de residentes de Uyuni hacia otras ciudades de Bolivia. De la misma forma, un importante flujo se dirigió hacia el exterior, en especial hacia las ciudades chilenas como Calama, Antofagasta e Iquique.

Hernán Veizaga afirma que ese denso éxodo fue inevitable para el poblado: "más de 1500 familias tuvieron que dejar este solar patrio. Sin temor a equivocarnos podemos asegurar que de los estantes y habitantes en Uyuni en los primeros 50 años del siglo xx, sólo quedaron no más de 5 familias...” (Veizaga, 2003, p. 1).

Con el cierre de la maestranza, la actividad y situación económica de su población fueron en descenso, evidenciando una tasa de crecimiento intercensal (1992-2001) del municipio, cuyo porcentaje mayor de habitantes se concentra en Uyuni, con la negativa cifra de -0.53 \% (Archivo Municipal de Uyuni, reportes censales 1992-2011). Si bien el rango cronológico es amplio, consideramos que no mide a cabalidad el proceso, porque Uyuni se despobló y repobló en un lapso menor.

La familia de Jeanette Campos Díaz, completamente nacida en Uyuni, emigró hacia Antofagasta (Chile) en pleno proceso de privatización de los ferrocarriles y el fin de la maestranza:

Llevamos alrededor de 15 años en Antofagasta, llegamos porque mi papá buscaba trabajo. Dejamos Uyuni y nos trasladamos con toda la familia. En Uyuni solo quedaron mis abuelitos y vamos a verlos de vez en cuando. Todos mis hermanos estudiamos en Chile... [entrevista a Jeanette Campos Díaz, uyunense residente de Antofagasta desde 1991, febrero de 2014].

El caso expuesto muestra una típica familia que rehízo su vida en las afueras de Uyuni. Sin duda, el impacto familiar de la privatización de ferrocarriles fue profundo. La división de núcleos familiares se expresó en la resistencia a abandonar la ciudad por parte de los ancianos, y así las visitas familiares fueron una modalidad de circulación por parte de uyunenses desplazados dentro o fuera del país.

Renán Cabrera, quien tenía 15 años al momento del cierre de la maestranza, recuerda lo siguiente: 
Me daba mucha pena, porque la gente decía que Uyuni se iba a quedar igual que el campamento minero de Pulacayo, vacío. Yo que tanto amaba desde niño mi pequeña ciudad, empecé a preocuparme. Los ferroviarios paralizaron la estación protestando contra el gobierno de Gonzalo Sánchez de Lozada, pero el Regimiento Loa estaba listo para actuar [entrevista a Renán Cabrera, uyunense residente de La Paz, administrador de uyuniweb.com, febrero de 2014].

Entonces, el proceso de desmantelación también contó con la ayuda del brazo armado del Estado ante una comunidad dislocada.

El panorama de la ciudad en los años 1995 y 1996 nos remite, según las memorias de nuestros informantes, a una gran cantidad de casas que anunciaban su venta en las puertas o en las ventanas. Era la expresión de la emigración y las ganas de olvidar el proceso de privatización.

Renán Cabrera agrega:

Muchos se dedicaron a taxistas en Uyuni, en la actualidad lo siguen siendo, otros se fueron a diferentes ciudades de Bolivia [...] Mi padre decía: ¿A qué se puede dedicar la gente en Uyuni? No hay trabajo. Un gran porcentaje de uyunenses se fueron, creyendo que salir de Uyuni significaba progreso, muchos progresaron afuera, todos vendimos nuestras casas, la mayor tontería que hicimos.

\section{El turismo: reconversión y repoblamiento}

Los procesos de desmantelamiento de ferrocarriles y el correlativo desplazamiento de la población antecedieron la fama mundial que adquiriría el salar de Uyuni al final de los años noventa gracias a la difusión de imágenes en distintos portales de internet. Desde el segundo lustro de la década de 1990, Uyuni y su gran salar comenzaron a interesar a miles de europeos que, poco a poco, empezaron a llegar a una ciudad que estaba prácticamente vacía. De este modo, se inauguró una nueva dinámica económica en el poblado, manifestándose una reconversión pero también una nueva forma de dependencia directa frente al flujo de visitantes desde inicios del siglo xxi. Por ejemplo, si en 1995 hubo 4859 turistas que visitaron el salar de Uyuni junto con la reserva Eduardo Avaroa, para 2004, arribaron 47003. En 2007, las visitas a la reserva Eduardo Avaroa fueron 64196; hacia la isla de Incahuasi del salar de Uyuni se contabilizaron 50320 turistas, y al poblado de Uyuni se dirigieron 26469, según consignan los 
datos proporcionados por la Reserva Nacional de Fauna Andina Eduardo Avaroa (2013).

La ausencia de recursos humanos, así como la escasez de diversos servicios y equipamientos demandados por los flujos turísticos, impulsaron un proceso de inmigración hacia Uyuni. Cabe indicar que estos primeros flujos correspondieron a emprendedores provenientes desde la capital del país, quienes llegaron a formalizar y articular distintas rutas de interés turístico a través de numerosas agencias (entrevista a Juan Colque, uyunense que se desempeña en una agencia de turismo, febrero de 2013).

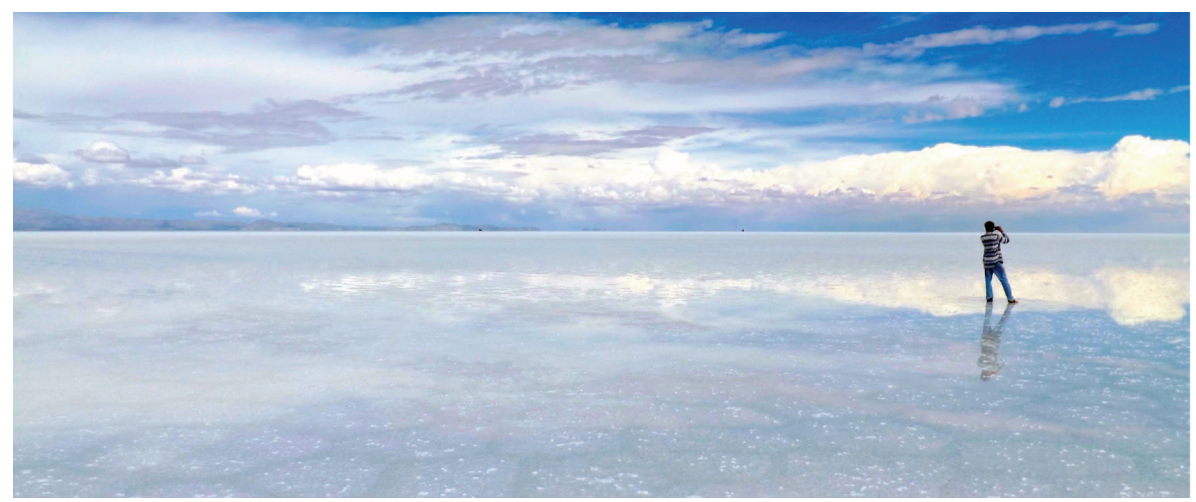

Fuente: Fotografía del autor (2013).

Figura 1. Turista en el salar de Uyuni

El turismo en los últimos 15 años ha dinamizado parcialmente algunos sectores de la economía de Uyuni: ha significado inversión en infraestructura, mejoramiento en algunos barrios por emprendimientos privados, construcción de hoteles, hostales, casas de descanso, restaurantes, almacenes, tiendas, bares, pizzerías, ferias artesanales, entre otros tipos de negocios. Ha permitido, además, el aumento de la renta de muchas familias directamente vinculadas con el turismo, y también un apogeo de taxistas, transportistas y grupos artísticos y culturales que ofrecen sus servicios patrimonializados (danzas, música andina, artesanías, pinturas, performances étnicas, etcétera). 
En la caracterización de las ocupaciones en Uyuni, en una encuesta realizada a 3186 personas por parte de funcionarios municipales, podemos ver que, en 2012, el comercio y los servicios relacionados con el turismo alcanzaban la sustancial cifra de 2429 personas, es decir, $76 \%$. En contraparte, podemos apreciar que actividades tradicionales del territorio, como la agricultura y la minería (Querejazu, 1996; Mesa Gisbert, De Mesa y Gisbert, 2007; López Pérez, 2011; Chungara, 2011; Galaz-Mandakovic, 2016), remiten a pequeños porcentajes: 6.7 y $1.7 \%$, respectivamente (Archivo Municipal de Uyuni, Plan de Desarrollo Municipal 2012).

Los trabajos en la construcción de hoteles, residenciales y casas, que significaron una fuerte expansión urbana, hicieron que en 2012 las ocupaciones laborales en este rubro alcanzaran $5.4 \%$ que, sumado al ítem denominado "producción y manufactura” relacionado con la construcción (elaboración de bloques, carpinterías, artesanías, entre otras), daría un porcentaje de 9.4 \% (Archivo Municipal de Uyuni, Plan de Desarrollo Municipal 2012).

Gran parte del repoblamiento de Uyuni tuvo que ver con el retorno de antiguos vecinos residentes, quienes en su mayoría se habían ido hacia Potosí, Oruro o La Paz. Otra porción de la población vio en Chile el lugar para migrar. María Pardo, dueña de un restaurante en Uyuni, recuerda:

Cuando cerró la maestranza ferroviaria, las cosas se pusieron muy malas en Uyuni, todo el pueblo estaba quedando vacío, no había negocios, mucha cesantía, no había esperanza porque el pueblo se estaba muriendo. Con mi esposo decidimos irnos a Chile. [...] primero llegamos a Calama. Mi esposo comenzó a trabajar en la construcción y yo me puse a trabajar como empleada en una casa. Estuve diez años en Chile... [entrevista realizada en febrero de 2013].

Nuestra informante añade:

Cuando supimos que Uyuni estaba tomando vida, que había movimiento dado por el turismo, que habían muchos "gringos" visitando el salar, con mi esposo nos vinimos de vuelta. Acá teníamos una casita que intentamos vender cuando cerró la maestranza pero nadie la quiso comprar, porque en realidad no había nadie en el pueblo. Así que la dejamos bien cerrada y a veces veníamos a Uyuni para visitar la casa y descansar algunos días y aprovechábamos de visitar nuestras familias que estaban en Potosí. [...] cuando ya vimos que la ciudad estaba tomando vida de nuevo, 
instalamos una cocinería, vendíamos colaciones y almuerzos, jugos, bebidas, casi todo para los "kankas" [rubios]. Ha sido lindo volver a la ciudad y nos ha ido bien con las ventas, la casa la ampliamos...

Situaciones parecidas nos reseñó la dueña de un reconocido hotel localizado en la calle Cabrera, quien también tuvo a su esposo trabajando en la maestranza. Cerrada esta, partió hacia la ciudad de La Paz: "El turismo nos hizo volver, la casa nuestra era grande y la convertimos en hotel y lo ganado lo hemos ido ahorrando y ampliando la casona”.

Debemos agregar que los hoteles en Uyuni son objetivamente más onerosos que cualquiera de tres o cuatro estrellas ubicado en la ciudad sede de gobierno: La Paz.

Victoria Ramírez, después de estar un tiempo en Chile, volvió a Uyuni e instaló un salón de té en el centro de la plaza principal de la ciudad:

Cuando me devolví a Uyuni, esto era como otra ciudad, había mucha gente de afuera, no hablo de los turistas, sino que hablo de gente que venía de otras ciudades de Bolivia, de Chile y que ahora tiene negocios en el centro. Cuando llegué, cerca del año 2000, jestaba todo muy caro! Por ejemplo, una casa en el año 1995 costaba cerca de 1000 dólares, ahora, en el 2013, una casa en el centro cuesta 150000 dólares, una locura ver cómo suben los precios de los terrenos y de las casas. Gracias a lo que he ganado con el turismo mis hijos pudieron estudiar... [entrevista realizada en febrero de 2013].

Visto el apogeo turístico de Uyuni, Renán Cabrera manifestó: "Personalmente estoy haciendo lo posible para regresar a Uyuni, y vivir allí, mi motivación ahora es económica, ya que en Uyuni cualquier comercio o negocio es factible”. Asimismo, comenta el cambio en los residentes:

El progreso llegó nuevamente a Uyuni, con fuerza, con el turismo. Cuando ya poblaron otras personas, paceños, orureños, potosinos, sobre todo los lugareños de los pueblos cercanos, amigos que aún viven en Uyuni me dicen que no quedan muchos uyunenses verdaderos viviendo en Uyuni, incluso alguien me dijo que solo pueden ser 500 personas de los antiguos... no sé, la verdad sí es así de extremo la situación, ya que ahora hay como 30000 personas viviendo. Muchas de estas personas que viven en Uyuni creen que están de paso, por esa razón no les interesa mucho el progreso de la ciudad. 
Victoria Ramírez se considera una "agradecida del turismo porque le permitió volver a su amado Uyuni”, no obstante acusa que la ciudad ha cambiado mucho:

Ya no está la familia uyunense, ya no queda nadie de las familias tradicionales, hay muchos conflictos entre los comerciantes. Los feriantes se pelean con los de Potosí y con los de Oruro, se pelean también con los que vienen desde el Área Dispersa... todos quieren vender acá.

En estos cuatro testimonios notamos en todo momento que los informantes siempre quisieron volver a su terruño, y lo hacen extensivo a gran parte de los uyunenses que se encuentran en otras ciudades o países. Una especie de uyunidad como rasgo fuerte de identidad local, un rasgo consolidado y melancólico, practicado a través de la cotidianidad y, quizás, la configuración de un discurso expresivo del mito del retorno (Galaz-Mandakovic, 2012). En ese sentido, la eventualidad del retorno, con independencia de su ejecución, vino a generar entre los emigrados uyunenses contenido, una memoria particular y densas expectativas respecto al poblado de origen.

\section{Migraciones indígenas al mundo urbano}

Por otra parte, atestiguando las nuevas dinámicas del poblado, además de las inmigraciones de foráneos, adicionado al retorno de antiguas familias, el turismo inauguró otro flujo migrante, el cual remitía a grupos de indígenas del área rural. Según datos recogidos en la municipalidad de Uyuni, desde mediados de la década de 1990 se plasmó un proceso de amplificación de las migraciones indígenas y rurales hacia el área urbana de Uyuni; los flujos provenían desde la llamada Área Dispersa, zona compuesta por centenas de pequeñas aldeas altiplánicas en donde escaseaba el agua y existían fuertes riesgos sanitarios, pauperización que caracterizaba a la ruralidad contigua de Uyuni en la que vivían numerosas comunidades indígenas. Debemos agregar que en el Área Dispersa de Uyuni se vivía la escasez de trabajo por la excesiva parcelación de la tierra, el deterioro de la fertilidad de los suelos y las restricciones de acceso al riego, aunado al uso de tecnologías no apropiadas y los factores climáticos. Entonces, los niveles de producción eran más bajos y los precios, desfavorables, lo cual reflejaba un panorama en que los ingresos procedentes de la actividad agrícola 
no cubrían los requerimientos de la unidad productiva familiar (Archivo Municipal de Uyuni, Plan de Desarrollo Municipal 2012).

Estas migraciones desde el área rural indujeron una sobrecarga demográfica y animaron un déficit de equipamientos públicos, de viviendas y de elementos básicos para la subsistencia: carencia de agua, ausencia de alcantarillados, de cobertura de instituciones de salud, educacionales, policiales, asistenciales, etc. Estos migrantes rurales se desenvolvían principalmente en el área de la construcción (albañiles, carpinteros, cargadores, etc.) y los servicios (aseo, choferes, cocineros, cargadores de equipaje, estafetas de hoteles, etc.). Otros grupos se dedicaban al comercio en las ferias, particularmente con la venta de frutas, verduras y ropa usada.

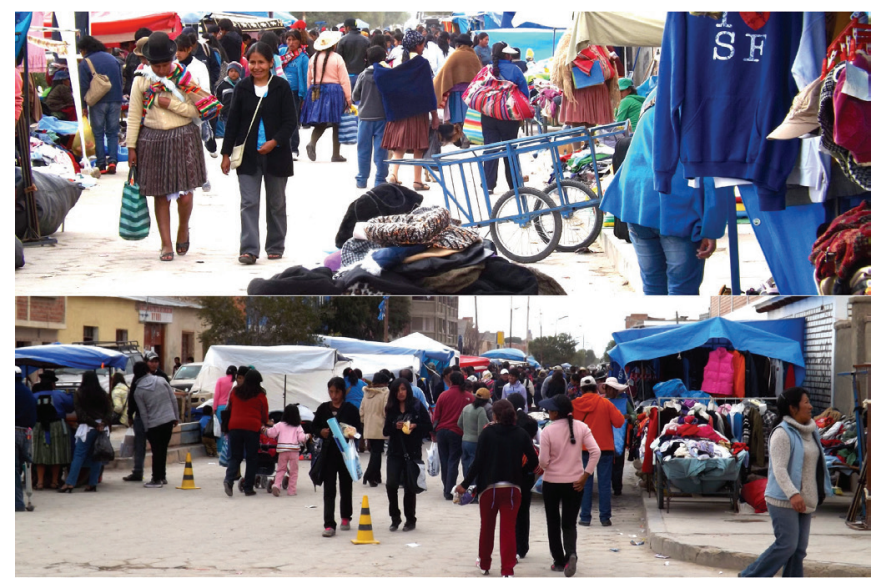

Fuente: Fotografías del autor (febrero de 2013).

Figuras 2 y 3 . Feria de Uyuni, en donde gran parte de los comerciantes corresponde a pobladores rurales que venden frutas, verduras, juguetes y ropa usada

A decir de Rosa Ramos, la población rural dejaba sus tierras pensando encontrar mejor calidad de vida. Sin embargo, la realidad era otra, porque los pobladores rurales se vieron obligados a ofrecer su mano de obra al sector terciario y de tipo informal por salarios ínfimos o, en el mejor de los casos, "se dedican a actividades comerciales por su propia cuenta, comercializando golosinas, baratijas, con el propósito de ganar [...] para su subsistencia” (Ramos, 2012, p. 58). 
En el Plan de Desarrollo Municipal de Uyuni, de 2012, se menciona que "en Uyuni se observa la migración interna [...] que ocurre en la jurisdicción municipal entre el contexto urbano y rural” (p. 34). Pero al mismo tiempo se indica que la ciudad no ofrecía oportunidades de empleo pleno, sino solo posibilidades laborales precarias, temporales e informales.

En palabras del alcalde de Uyuni Froilán Condori Ancasi (2012-2013), existía un "descontrol" con este movimiento de personas que venían del campo a la ciudad (entrevista realizada en febrero de 2013). Alberto André coindice con lo anterior, por lo cual era imposible poseer una cifra exacta sobre la cantidad de personas que continuamente se movilizaron en tales circuitos entre el campo y la ciudad. El principal problema para las autoridades radicó en ejecutar censos, porque la población indígena migrante en el municipio de Uyuni, al momento de realizarlos, retornaba a sus territorios rurales, entonces no alcanzaba a ser contabilizada y se constituía en invisible ante las estadísticas oficiales del municipio.

Ahora la pregunta es por qué los vecinos regresaban a los pueblos de origen. Muchas de las respuestas tienden a confluir en el miedo que tenían los campesinos en cuanto a la posibilidad de perder sus terrenos y casas en el área rural.

En el diario El Salar (núm. 47, 12 de diciembre de 2012) se abordaba esta problemática que generaba una desviación en los guarismos estatales, informando las medidas que el municipio llevaría a cabo para intentar controlar la situación: "Certificado de Registro Censal será exigido en todo trámite o pago en la alcaldía de Uyuni, a los que no porten este documento serán sancionados por las autoridades municipales".

En entrevista con el alcalde (2013), este indicó que el Certificado de Registro Censal de cada vecino contemplaba su nombre, el número de carnet, dirección postal o lugar de pernoctación, además del nombre del presidente de la Junta Vecinal y la firma del alcalde municipal. Este documento tendría la validez y duración de una gestión municipal, y las personas que no contaran con él serían multadas. Dijo: "sabremos si este vecino fue censado o no en esta ciudad".

En diciembre de 2012, en el diario El Salar se mencionaba lo siguiente: "este control cuantitativo permitirá a la alcaldía local de realizar un cruce de información entre los datos de inE y la base de datos de las Juntas Vecinales para saber qué cantidad de gente abandonó la ciudad con motivo del censo”. 
Más adelante, en el mismo diario se consigna: "para el cumplimiento de este control, el Concejo Municipal de Uyuni ya había emitido una ordenanza municipal en octubre del año 2012 invocando a los ciudadanos a censarse en el municipio de Uyuni con la finalidad de tener mayores recursos económicos y beneficiar de mejor manera a la población”.

Este control anatomopolítico (Foucault, 2008) evidenció la resistencia y los reclamos de los migrantes rurales, quienes acusaban discriminación y persecución porque, supuestamente, su presencia en las calles "afectaba al turismo".

Por otra parte, los alcaldes manifestaban que las cifras censales no representaban la realidad local. De todos modos, podemos citar las realidades estadísticas según el Estado boliviano.

\section{CuAdro 1. Censos 2001 y 2012}

\begin{tabular}{ccccccc}
$\begin{array}{c}\text { Total departamento } \\
\text { Antonio Quijarro }\end{array}$ & Censo 2001 & $\begin{array}{c}\text { Total } \\
\text { Uyuni }\end{array}$ & Censo 2012 & Total \\
& & & & & Uyuni \\
37428 & 9184 & 9521 & 18705 & 14410 & 15108 & 29518 \\
\hline
\end{tabular}

Fuente: Elaboración propia con base en datos del Instituto Nacional de Estadística de Bolivia.

De acuerdo con los datos oficiales, entre 2001 y 2012 el poblado tuvo un incremento de 10813 habitantes, es decir, un aumento demográfico de $36.6 \%$, sin duda, una cifra significativa.

El exalcalde Alberto André nos mencionó que la realidad estadística de Uyuni no se condecía con la realidad cotidiana, por tanto, los ingresos y subvenciones del Estado eran mínimos y las necesidades, crecientes.

Entonces, para revisar tal afirmación, podemos ver que en la gestión municipal de 2011 se recibieron alrededor de 18 millones de bolivianos (2 597940 dólares), recursos asignados por el Tesoro General de la Nación mediante el Ministerio de Economía y Finanzas Públicas; entre tanto, la recaudación propia del municipio en los últimos años había promediado unos dos millones de bolivianos (288 660 dólares); así pues, el presupuesto anual llegaba aproximadamente a los 20 millones de bolivianos (2 886600 dólares), cifra considerada 
insuficiente para atender la gran demanda de proyectos que solicitan las múltiples comunidades urbanas y rurales, así como las juntas de vecinales (Archivo Municipal de Uyuni, Plan de Desarrollo Municipal 2012).

En febrero de 2013, el alcalde Condori Ancasi señalaba:

Mantenemos el doble de habitantes con el mismo presupuesto, la misma cantidad de servidores públicos, es un esfuerzo grande, yo calculo por lo menos a que aquí en la ciudad viven alrededor de 30000 habitantes, esto salió de la sistematización de la viviendas... mucha gente regresó con el boom del turismo; por lo menos promedio unos 60000 habitantes y con un presupuesto de 20 millones jes imposible!, por eso los sueldos son bajos en Uyuni, Uyuni es una ciudad cara, por eso no quiere trabajar la gente de la región, tengo funcionarios de otros departamentos y no siempre trabajan como un hijo de su pueblo. La perspectiva más grande es que lleguemos a 40000 habitantes. Sería un récord doblar la cantidad de habitantes para que de manera per cápita puedan mejorar los recursos para infraestructura y las múltiples necesidades de la comuna de Uyuni.

La municipalidad en todo este proceso consideró necesario establecer innovaciones en las relaciones políticas con algunos ayllus (forma tradicional de comunidad en los Andes) que colindaban con los bordes de la ciudad. Los ayllus que conforman la provincia Antonio Quijarro son Coroma, Qhasa, Tawca, Pallpa, Anduga, Chikoka, Jila, Sullk’a y Yura. Estas comunidades ayudaron a recopilar algunos datos de la población indígena migrante en la ciudad.

El cuadro 2 muestra los principales pueblos indígenas u originarios de autoidentificación en el municipio, de acuerdo con el Instituto Nacional de Estadística de Bolivia (INE, 2012).

CuAdro 2. Principales pueblos originarios que habitan en Uyuni con base en la autoidentificación

\begin{tabular}{lc} 
Quechua & $52.87 \%$ \\
\hline Aymara & $24.16 \%$ \\
\hline Ninguno & $22.63 \%$ \\
\hline Otro & $0.17 \%$ \\
\hline
\end{tabular}

Fuente: Elaboración propia con base en datos del Instituto Nacional de Estadística de Bolivia, censo 2012. 
Por su parte, en el cuadro 3 se observan los principales idiomas hablados en el municipio, según los datos recopilados por la misma entidad, al 2012.

CUADRo 3. Idiomas hablados por la población de Uyuni

$\begin{array}{lc}\text { Español } & 40.75 \% \\ \text { Quechua } & 28.37 \% \\ \text { Aymara } & 12.85 \% \\ \text { Extranjero } & 6.41 \% \\ \text { Otros } & 11.62 \%\end{array}$

Fuente: Elaboración propia con base en datos del Instituto Nacional de Estadística de Bolivia, censo 2012.

De todos modos, debemos mencionar que el crecimiento demográfico fue significativo, al menos así quedó demostrado en el censo de 2015: "Uyuni también creció bastante pero no solo por la quinua sino también por el turismo, tenía 18705 ciudadanos y subió a 29 518” (Instituto Prisma, 2015, p. 13).

\section{La precariedad de Uyuni: paradoja y asimetrías de una capital turística}

La ciudad turística derivó en una fragmentación urbana: por un lado, los barrios turísticos en la zona urbana, lugares por los cuales día a día transitaban miles de viajeros con grandes bolsos y cámaras fotográficas; por el otro, los barrios de indígenas en las periferias del poblado.

Según los datos recogidos en nuestro trabajo etnográfico, gran parte de los pobladores uyunenses que se reconocían como indígenas se sentían prácticamente proscritos en el centro urbano, acusando la inaccesibilidad a diversos servicios por su carestía: arriendos de viviendas, precios de las comidas, inaccesibilidad a la compra de distintos insumos, nulo acceso a diversión, además de discriminación y prejuicios étnicos por parte de propietarios de restaurantes y comercios con dueños foráneos. Cabe indicar que en el centro de la ciudad se evidenció el fin del carácter residencial para dar paso a una infraestructura de servicios: hoteles, restaurantes, pizzerías, servicios telefónicos y de internet, bares, ferias, mercados y comercios de artesanías. Esas arquitecturas monumentales para el turismo manifestaban un fuerte contraste con las arquitecturas 
de autoconstrucción de la población neta y migrante indígena de Uyuni, expresión patente de estos dos tipos de ciudades que residían en un mismo territorio.

La ciudad de Uyuni estaba desintegrada, la línea o los márgenes del centro urbano marcaban una frontera entre turistas y población autóctona; la ciudad manifestaba la precariedad y pobreza evidente en las residencias periféricas, pobreza que también era fotografiada por los turistas en el marco de la exotización de la miseria. Decimos esto porque era muy usual ver en Uyuni una gran cantidad de turistas fotografiando a niños huérfanos, indígenas, basureros colapsados, casas precarias, charcos de agua en las calles de las poblaciones, 0 bien, letreros municipales llamando a "no botar basuras" en lugares impropios. Tales particularidades eran altamente "atractivas" para los turistas europeos y norteamericanos.

No obstante, este apogeo de turistas y de empresas foráneas debió cruzarse con una ciudad frágil en su integridad. Por ejemplo, en el tema de la vivienda, desde principios del siglo xxI, las políticas gubernamentales bolivianas que se aplicaron para facilitar el acceso no permitieron que los sectores más pobres accedieran a este derecho por los mismos problemas derivados de la migración y circulación por el territorio. En consecuencia, el déficit de vivienda era considerado elevado en la primera década del siglo xxI, dado el crecimiento demográfico impulsado por la migración rural a la ciudad. Además hubo una interrupción de los programas estatales financiados con aportes laborales y patronales (Archivo Municipal de Uyuni, Plan de Desarrollo Municipal 2012).

Para 2012, el déficit de viviendas en el municipio era elevado: viviendas propias, 3 750, y viviendas en alquiler, anticrético u otros alcanzaban las 1560 (Archivo Municipal de Uyuni, Oficio No 43 sobre viviendas, 2012). Debido a la inmigración y el crecimiento poblacional en las áreas periurbanas, se rebasó la capacidad de atención municipal, en esa lógica se empequeñeció el acceso a la vivienda y a suelos adecuados, en especial para los sectores sociales de bajos ingresos. Los factores que incidían en este problema eran las extemporáneas políticas de subsidio para la vivienda social, la inseguridad jurídica sobre el suelo urbano y la defectuosa implementación de los instrumentos normativos de ordenamiento y planificación territorial de los asentamientos urbanos y rurales.

Todo este devenir de turistas impactó también en la inflación de los precios de insumos de primera necesidad, además de que eran altos los precios en 
comparación con otras ciudades de Bolivia utilizando los hoteles y restaurantes como referencias. Este proceso inflacionario se debía, en parte, al mayor poder adquisitivo de los turistas en disparidad con el poder adquisitivo de la población local.

Del mismo modo, existía otro proceso inflacionario importante, el cual remitía a las alzas de precios del suelo y de las residencias. El suelo se convirtió en un bien escaso y preciado y territorial y económicamente determinado, es decir, los precios dependían de su proximidad al centro de la ciudad: al barrio de los turistas.

En la jurisdicción municipal de Uyuni se vivían fuertes problemas relacionales por efecto de conflictos limítrofes en las propiedades de terrenos entre cantones, ayllus, comunidades y propiedades familiares; en aquellos sectores donde se contaba con el saneamiento de tierras los problemas eran mayores, implicando fuertes pleitos comunitarios que incluyeron la violencia física y moral (entrevista a Froilán Condori Ancasi, febrero de 2013).

En algunos lugares del municipio existe mucha intransigencia para realizar el saneamiento de los terrenos, que en muchos casos son grandes propiedades y prefieren mantener en reserva este hecho, o cuando las poblaciones empobrecidas piensan que el catastro municipal es para cobrar impuestos [entrevista a Froilán Condori Ancasi, febrero de 2013].

Lo anterior daba pie a que el municipio careciera, en 2013, de un plan de ordenamiento territorial, generando la imposibilidad de optimizar las modalidades de uso del suelo.

Por otra parte, la inmigración y el crecimiento poblacional en las áreas periféricas de Uyuni sobrepasaron la capacidad de atención municipal, además del descontrol en la planificación urbana por efecto de gestiones deficitarias, en especial para los sectores habitados por grupos de bajos ingresos, generalmente familias compuestas por campesinos y antiguos mineros. Esta situación dio pie a viviendas autoconstruidas que se caracterizaban por su precariedad material y sanitaria. En ese marco se inscribía la elevada tasa de mortalidad infantil en Uyuni, una de las más altas del país: en 2005, fue de 81 por 1000 nacidos vivos; en el departamento de Potosí, alcanzó en el mismo año 66 por 1000 nacidos vivos (Archivo Municipal de Uyuni, Plan de Desarrollo Municipal 2010, p. 34). 
A pesar de estas sorprendentes cifras, que expresaban las inequidades y la marginalidad socioeconómica profunda, remitida por ejemplo en varios casos a los efectos de la insalubridad del agua, además de su deficitario acceso, la deficiente alimentación, la vulnerabilidad ante fenómenos climáticos y la precariedad en la atención de la salud, el informe del Plan de Desarrollo Municipal de Uyuni atribuía, confusamente, esta realidad a temas educativos: "La educación es una de las variables que tienen mayor asociación con la sobrevivencia infantil, así es reconocido que cuanto mayor es el nivel de instrucción materna, mejores son los cuidados que recibe el niño" (Archivo Municipal de Uyuni, Plan de Desarrollo Municipal 2010, p. 34). De este modo, el municipio soslayaba sus propias responsabilidades.

La realidad deficitaria en la calidad de vida, además de las altas cifras de mortalidad infantil, se evidenció en el índice de proyección de la esperanza de vida en Uyuni, que fue uno de los más bajos de Bolivia; por ejemplo, para el quinquenio 2000-2005, la esperanza de vida en el departamento de Potosí, al cual pertenece Uyuni, fue de 57.78 años, cifra que luego es extendida como proyección en el periodo 2000-2030 (Censo INE, 2012).

Otros problemas estaban referidos a la insuficiencia de infraestructura de servicios básicos, como el agua potable, la cual en el año 2012 poseía una cobertura que alcanzaba solo a $69.32 \%$ en el nivel municipal. La cobertura del servicio de alcantarillado llegaba a $22 \%$ en la ciudad de Uyuni; los poblados aledaños y las casas en la periferia uyunense carecían completamente de este servicio (entrevista a Froilán Mamani, febrero de 2013).

Asimismo, atestiguamos como insuficientes las actividades de recolección o retiro de residuos sólidos domiciliarios, así como de residuos de mercados, mataderos, establecimientos de salud, además de los residuos procedentes de limpieza de calles, avenidas y zonas recreativas, escombros de obras de construcción y demoliciones, residuos de pozos negros, centros comerciales, oficinas y animales muertos; asunto que las gestiones municipales no pudieron superar por la escasez de recursos humanos y financieros durante un largo periodo. Todo esto originó la existencia de innumerables archivos de basura acumulados día a día en las periferias, expandiéndose hacia las zonas centrales como resultado de las mismas circulaciones de viajeros. También podemos señalar que los mismos vecinos depositaban su basura en distintas esquinas, y algunos de ellos manifestaban cierta idea de resistencia ante los turistas y las diversas agencias 
que increpaban a los vecinos por "afectar al turismo" con sus archivos residuales domiciliarios. De esta forma, se construía una discursividad conflictiva, teniendo a la basura como contenido que administraba tales tensiones.

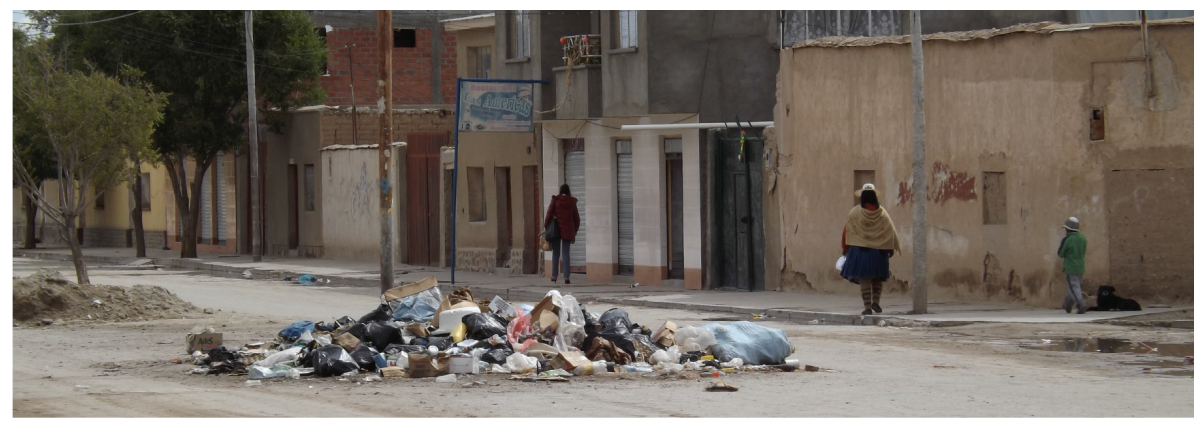

Fuente: Fotografías del autor (febrero de 2013).

FIGURA 4. Las tensiones entre las agencias de turismo y los vecinos, incluyendo al municipio, estaban remitidas a la acumulación de basura en las esquinas de cada cuadra. En nuestro trabajo de campo pudimos notar esta particular apropiación del espacio por parte de los uyunenses, configurando una tónica marcada por los problemas sanitarios y la constitución de una estética "desfavorable" y protesta contra las dinámicas del turismo

En el municipio, la cobertura del servicio de energía eléctrica para 2012 alcanzaba solo 62.07 \% en el nivel urbano. Sin embargo, la labilidad del servicio quedaba en evidencia al momento de ocurrir lluvias y nevazones, situación que estimulaba que el servicio estuviera suspendido por más de 48 horas, lo cual implicaba riesgos sanitarios, al menos en el hospital y carnicerías, y también problemas de comunicación. Se sumaba a lo anterior la escasez de áreas verdes, espacios públicos recreativos y culturales en beneficio de la población local (Archivo Municipal de Uyuni, Plan de Desarrollo Municipal 2012).

La misma municipalidad de Uyuni testificaba que existía una "crisis económica y social creciente" (Archivo Municipal de Uyuni, Plan de Desarrollo Municipal 2012, p. 110), indicando que concurrían una falta de medidas económicas adecuadas, el hecho de que no existía reactivación económica para la generación de empleos y desarrollo productivo, y el aumento constante de la inmigración por condiciones de pobreza rural, lo cual tornaba insuficientes 
las inversiones públicas y privadas en el municipio, implicando la disminución de los escasos recursos que se percibían desde el Estado. Al mismo tiempo se evidenciaba la falta de atención a la producción agrícola, pecuaria y minería, temiendo por parte de las autoridades municipales cierta inseguridad alimentaria, por ello, la ciudad se proyectaba en un desborde.

En el cuadro 4 se expone la situación de pobreza en la jurisdicción municipal de Uyuni, de acuerdo con los datos del INE, para 2001.

Cuadro 4. Situación de pobreza en la jurisdicción municipal de Uyuni para 2001

\begin{tabular}{lc} 
Población pobre urbano & 3408 \\
\hline Población pobre rural & 7122 \\
\hline Población en extrema pobreza urbano & 13 \\
\hline Población en extrema pobreza rural & 4158 \\
\hline
\end{tabular}

Fuente: Elaboración propia con base en datos del Instituto Nacional de Estadística de Bolivia.

Según estos datos, podemos apreciar que el total de la población relacionada con la pobreza sumaba 14701 personas en un universo de 18705 habitantes correspondientes a la primera sección Uyuni del departamento Antonio Quijarro, es decir, un voluminoso porcentaje de 78 \% (Censo INE, 2001).

En tanto, el cuadro 5 presenta la estratificación de la pobreza en el municipio de acuerdo con el INE (2001).

Cuadro 5. Situación de la estratificación de la pobreza en la jurisdicción de Uyuni, 2001

\begin{tabular}{|c|c|c|c|}
\hline $\begin{array}{l}\text { Necesidades básicas satisfechas } \\
\text { en área urbana }\end{array}$ & $9.82 \%$ & $\begin{array}{l}\text { Pobreza moderada } \\
\text { urbano }\end{array}$ & $34.08 \%$ \\
\hline $\begin{array}{l}\text { Necesidades básicas satisfechas } \\
\text { en área rural }\end{array}$ & $2.55 \%$ & $\begin{array}{l}\text { Pobreza moderada } \\
\text { rural }\end{array}$ & $36.63 \%$ \\
\hline Umbral de pobreza urbano & $55.98 \%$ & Indigencia urbana & $0.13 \%$ \\
\hline Umbral de pobreza rural & $9.44 \%$ & Indigencia rural & $51.38 \%$ \\
\hline
\end{tabular}

Fuente: Elaboración propia con base en datos del Instituto Nacional de Estadística de Bolivia. 
En pleno apogeo turístico, podemos ver que en la ciudad se manifestaba el mayor porcentaje de población bajo el umbral de pobreza (55.98 \%).

Según la fundación Codespa (2015), en la zona de Uyuni, 80 \% de sus habitantes vivía en situación de pobreza, y se acusaba que las posibilidades de trabajo eran mínimas: "A pesar de ser una zona de las más turísticas del mundo, las poblaciones indígenas no pueden obtener ingresos del turismo".

En temas vinculados con la escolaridad, se observaban precariedades referidas a la desigualdad de oportunidades para indígenas, mujeres, campesinos, personas con capacidades diferentes, adolescentes trabajadores y pobladores que por diversos factores se encontraban en situación de exclusión y marginalidad. Lo anterior daba pie a que existiera una tasa de analfabetismo que llegaba a $5.14 \%$ en varones y $20.27 \%$ en mujeres (Archivo Municipal de Uyuni, Plan de Desarrollo Municipal 2012). Esta condición era estimulada por la deserción escolar por efecto de que niñas y niños de familias migrantes o empobrecidas se insertaban tempranamente en el mundo laboral conectado en general con el turismo y distintos servicios relacionados.

Si bien la ciudad manifiesta una inyección migrante proveniente del área rural, el municipio temía que ocurrieran tres procesos negativos. El primero tenía que ver con la gran asimetría demográfica entre el área urbana en desmedro de la población rural y campesina; es decir, la desruralización y desertificación demográfica. El segundo, con el incremento sostenido de la ciudad, que derivó en una carencia de equipamientos públicos. Y un tercero referido a la exclusión de la población indígena en el área urbana (entrevista a Froilán Condori Ancasi, febrero de 2013).

El surgimiento de poblaciones periféricas por parte de grupos indígenas ocurrió en el contexto de problemas sanitarios, porque no contaban con sistemas eficientes de abastecimiento de agua potable y evacuación de aguas servidas.

En el lapso estudiado, eran usuales los problemas de salud relacionados con los dramas digestivos, como se constató en el hospital de Uyuni, donde, curiosamente, carecían de una cuantificación del problema por considerarlo "normal”. No obstante, afirman que existía "un gran número de enfermos por beber agua mala”. Los nuevos vecinos de Uyuni utilizaban fuentes de agua en donde acumulaban recolecciones en poblaciones vecinas. De este modo, surgieron pozos con extracción manual de agua, o bien recurrían a ciertas vertientes y 
a pequeños riachuelos. Alberto André Guamán nos comenta que cuando ejercía como alcalde en Uyuni, tuvo que ir muchas veces a las nuevas poblaciones para concientizar a los vecinos de las prácticas negativas que estaban llevando a cabo, indicando que las familias desconocían la calidad del agua, que no le aplicaban ningún tratamiento, además de tener el agua acumulada en tambores infectos y con precarias protecciones, situación que inducía a la enfermedad en niños, adultos y ancianos.

Gracias a los extensos recorridos y etnografías que realizamos en los barrios periféricos de Uyuni, pudimos darnos cuenta de que en varios de ellos existían fuertes pestilencias y una gran cantidad de insectos y ratones: vectores de distintas enfermedades e infecciones; además de altas acumulaciones de basura y pozos en donde se depositaban aguas servidas. Sin embargo, a pocos metros se hallaba unos de los puntos turísticos más atractivos de la localidad: el Cementerio de Trenes (transferido al municipio a través del Decreto Supremo, $\mathrm{N}^{\circ}$ 25.973, 11 de noviembre 2000, Archivo Gaceta Oficial de Bolivia), en donde el precio de una agencia de turismo para visitar tal sector y luego el salar era altísimo, ofreciendo traslado, guía, alimentación y alojamiento, que incluso superaba el ingreso per cápita de Bolivia (2 576 dólares anuales, 2009-2013).

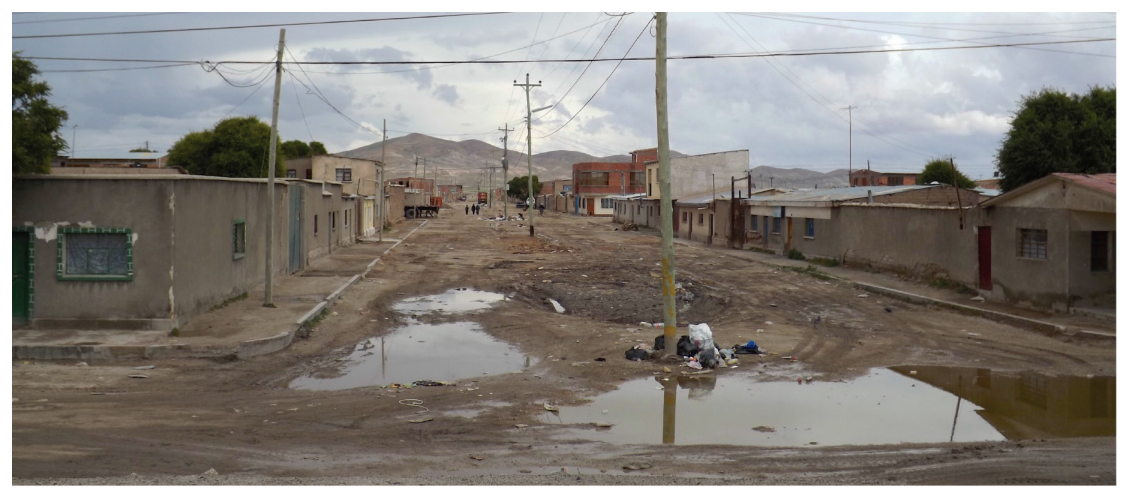

Fuente: Fotografía del autor (febrero de 2013).

FIgURA 5. Poblaciones de Uyuni, en donde la presencia de charcos, basura y problemas sanitarios caracterizan la periferia, repercutiendo en la calidad de vida de los habitantes, quienes, vista la desatención de las autoridades municipales y estatales, expresan críticas hacia el olvido, así como hacia la soberbia de los distintos agentes turísticos 
La deficitaria organización en la disposición adecuada de los residuos sólidos y tratamiento de aguas residuales contribuyó a la contaminación del agua disminuyendo la calidad de vida de la población que utilizaba las fuentes de agua para su consumo: se consideraba que 80 \% de las enfermedades tenía origen hídrico (Archivo Municipal de Uyuni, Plan de Desarrollo Municipal 2012).

En el área laboral, según los datos oficiales del municipio cabecera de la provincia, la población ocupada por categoría en el empleo era como sigue: asalariados, 1 843; independientes con remuneración, 3 753; independientes sin remuneración, 401; y la población en edad escolar que trabajaba era de 576 niños (Archivo Municipal de Uyuni, Plan de Desarrollo Municipal 2012).

Cabe indicar que el empleo generado en los últimos tiempos estaba marcado por los bajos ingresos, la inestabilidad laboral y la recurrencia al trabajo durante largas jornadas. En este tipo de empleo se concentraban las unidades de pequeños artesanos, comerciantes, trabajadores de servicio, trabajadores por cuenta propia, muchos de ellos vinculados con el turismo que incluso recurría al trabajo infantil (entrevista a Alberto André Guamán, febrero de 2013).

Froilán Mamani indicó:

en Uyuni hay mucha plata pero también mucha pobreza, hay gente que es muy rica gracias al turismo, pero no todos acceden a esos dineros. Eso escapa a lo que puedo hacer como alcalde. Por eso, muchos uyunenses se van porque la ciudad, por culpa de estos señores del turismo, se puso muy alto el costo de la vida, todo es muy caro... [entrevista realizada en febrero de 2013].

El Plan de Desarrollo Municipal de la ciudad estudiada señalaba que también había emigrantes en Uyuni, quienes respondían a aspectos de orden estructural que tienen que ver con la situación económica que no permitía a las familias rurales reproducir su fuerza de trabajo. El lugar y destino de los emigrantes se remitían a Challapata, Oruro, Potosí, Santa Cruz, Yacuiba, Sucre, Tarija, La Paz y los países de Argentina y Chile (Archivo Municipal de Uyuni, Plan de Desarrollo Municipal 2012).

El departamento de Potosí y el de Uyuni estaban inscritos en aquella trama emigrante. Sin embargo, las voces optimistas en Uyuni nos hablaban del "desarrollo" de la ciudad: 
Ciertamente hay alto movimiento económico, una medida de lo mismo lo brinda la continua instalación de más agencias de bancos, las últimas fueron del Banco Unión y del Banco Nacional. Evidentemente existe un auge de construcciones, entre antiguos y nuevos uyunenses, merced a un trabajo tesonero están encarando proyectos de envergadura, me parece digno de encomio y merecedor de las mayores felicitaciones, ese arriesgar en proyectos que a la larga beneficiarán a toda la población, evitando la emigración a la que antaño nos veíamos forzados [Víctor Chungara, portal Uyuniweb, 2011].

Pero esta confusa idea de "desarrollo" omitía la desigualdad, la distribución negativa o deficitaria de los ingresos que generaba el turismo, por ello fueron muchos los que partieron desde Uyuni por efecto de la desintegración y encarecimiento integral del costo de vida.

El Mercurio de Antofagasta (Chile), en su edición del 24 de diciembre de 2012, daba cuenta de la conformación de un campamento ilegal por parte de un gran número de inmigrantes extranjeros: peruanos, paraguayos y bolivianos; 24 familias constituyeron el comité La Lucha es Posible. En aquel reportaje se mencionaba el caso de la ciudadana uyunense Edith Pérez como ejemplo de uyunenses que buscaban "mejores horizontes" dada la pobreza en las tierras de origen.

\section{Comentarios finales}

Como hemos señalado, el turismo ha significado para Uyuni una trama de distintas articulaciones, movimientos y derivaciones en el transcurso de la diacronía regional que se retícula y expande desde la última década del siglo xx. La naturaleza se transformó en un elemento más, en un dispositivo o componente utilizable que comenzó a ser administrado capitalistamente (Fischer-Kowalski y Haberl, 2000), derivando en una forma de gestión e intervención en el territorio, en el acceso a la "propiedad" de los recursos del medio, los que, en la práctica, fueron privatizados en aras de intervenirlos, recorrerlos y exhibirlos como maravilla particular del orbe.

La configuración de Uyuni como capital turística de Bolivia, con sus circuitos de desiertos blancos y lagunas de colores, ha significado un irrupción masiva de paseantes que dinamizaron parcialmente tal periferia del Estado boliviano. 
Decimos parcialmente porque el turismo se fundó como nuevo dispositivo en la constitución de asimetrías en la distribución de beneficios, en el agotamiento y alteración de los recursos culturales y naturales, y en el subdesarrollo comunitario, en donde el Estado fue disipado, en los hechos, en cuanto al ejercicio de una influencia en una ciudad turística que manifestaba una estructura de empobrecimiento. Este dispositivo turístico revelaba la reproducción de la riqueza alóctona, las formas salvajes de cómo obtenerla, significando el fortalecimiento del capital por sobre o en desmedro de los grupos autóctonos (Bunker y Ciccantell, 2005). Como dijo Bauman: “La 'economía' -el capital; o sea, dinero y otros recursos necesarios para hacer las cosas, para ganar más dinero y hacer aún más cosas- se desplaza rápidamente; lo suficiente para mantener un paso de ventaja sobre cualquier gobierno (territorial, claro está) que intente limitar y encauzar sus movimientos” (2010: 75). A esto debemos incluir las precariedades legislativas respecto al trabajo de hombres, mujeres y niños de Bolivia.

La inscripción de Uyuni en la economía global de consumo visual se ejerció constituyendo una asimetría, aquello como resultado de la economía global policéntrica (Castells, 2006), que va produciendo espacios capitalistas y nodos turísticos con desarrollos desiguales y jerarquizados. Este tipo de articulaciones de los nodos turísticos funcionan con base en el orden exógeno (Becattini, 1992), articulándose además con los requerimientos de los consumos burgueses extranjeros y nacionales.

En esa producción de una geografía de consumo visual, contemplativa y eurocéntrica, la economía regional del sudoeste boliviano se constituyó como parte de un mosaico interconectado de desarrollos geográficos desiguales (Harvey, 2014). Esto es, el turismo fraccionó el sudoeste boliviano y una parte de él inauguró flujos interconectados con el orbe capitalista. A decir de Harvey: "los desarrollos geográficos desiguales enmascaran convenientemente la auténtica naturaleza del capital” (2014, p. 161). De ese modo, es posible aseverar que las asimetrías entre diferentes territorios pasaron a residir ya no solo entre los tipos de bienes o servicios que cada uno produce, "sino más bien en la posición de la cadena en que se ubiquen las actividades económicas que se desenvuelven en cada una de esas unidades territoriales” (Sztulwark, 2013, p. 280). En pocas palabras, el turismo dinamizó una economía, pero no funcionó como una apuesta dinámica o integradora (Levin, 1960), tanto en el nivel local como 
regional, solo reprodujo desigualdades y categorías coloniales para expandir los usufructos de tal consumo visual que favorece, hasta hoy, a un colectivo alóctono. Por ello, el Plan de Desarrollo Municipal acusaba que la actividad turística del ayuntamiento se desarrolló enfatizando solamente el componente económico de determinados sectores, por lo que afirmaba: "esta situación ha impedido que las comunidades rurales y otros sectores sociales sean gestores y beneficiarios de esta actividad, imposibilitando que el ecoturismo se constituya en una opción de desarrollo productivo sostenible" (Archivo Municipal de Uyuni, Plan de Desarrollo Municipal 2012, p. 122). Al mismo tiempo acusaba que el turismo no había permitido superar las deficiencias en infraestructura vial, servicios básicos y comunicaciones.

El impacto de esta forma de economía departamental se reflejaba en la segregación urbana de Uyuni, produciéndose una dualidad en la cual coexistían paralelamente un sector capitalista, de turistas consumistas, y una periferia: un sector tradicional, pauperizado, con corporalidades dispuestas al sacrificio laboral y también, sin quererlo, a la fotografía de exotización por parte de los viajeros.

De igual manera, el turismo llevó aparejada una desintegración de los radios regionales y locales; es decir, el desarrollo del turismo en Uyuni incorporó nuevas formas de concentración de flujos financieros rompiendo con las tendencias tradicionales de la región. Esto implicó la conformación de una población foránea que manifestó fuertes diferencias con las población local. Desde allí, con este control y tendencia colonizante del neoempresariado, surgieron jerarquías sociales nuevas, en este caso, resurgió la proletarización y disciplina de la población con base en las calculadas relaciones capitalistas.

Cada uno de estos procesos relacionales con base en la capitalización de la mano de obra expresaba una jerarquización completamente vertical entre las empresas alóctonas y los proveedores locales; situación que luego fue transmitida entre los propios trabajadores del turismo en cuanto a cómo se relacionaban con los proveedores de las empresas transnacionales (Ardenti y Vrain, 1999), y con la población indígena. No quepa duda de que estas relaciones capitalistas estaban fundadas en la coerción económica y en la carencia de instituciones de seguridad laboral colectiva (Ardenti y Vrain, 1999). 
Con base en lo anterior, se puede afirmar que los esquemas de producción capitalistas mostraron que el equilibro y la simetría del desarrollo territorial es la irregularidad, lo inusual; en este sentido se puede decir que los esquemas de producción exhiben que el equilibrio, para no hablar del crecimiento equilibrado, es la excepción y no la regla en el capitalismo. S. Ferrer indicó que las desproporciones son más frecuentes y que el crecimiento, al ser esencialmente desigual, produce crisis de manera inevitable (2009, p. 2); crisis generadas hacia un sector del territorio, aquel que no estaba articulado con las ganancias, pero sí con los efectos colaterales, así como también el ofrecimiento de mano de obra, viviendo además la discriminación étnica y la exclusión, con corporalidades fotografiables como recuerdo colonial de turistas sorprendidos por ciertos tipos de rostros, labores, pieles y cuerpos.

La metanarrativa surrealista del salar de Uyuni se desarma ante la pobreza del poblado, al mismo tiempo es una periferia del Estado por la influencia mayor que tienen los capitales privados que invirtieron en distintas logísticas y transformaron el territorio. En ese sentido, el territorio estaba vigorosamente jerarquizado, manifestándose sobre todo en macrodiferencias, entre entidades nacionales, regionales y urbanas, que eran graduales y continuas: "se diferencian claramente: se oponen sosteniéndose mutuamente” (Veltz, 1999, p. 54).

Nuestras consideraciones críticas hacia las asimetrías y derivaciones del turismo están necesariamente remitidas a la urgencia de implementar un desarrollo que se relacione y articule con la comunidad local de mejor manera, satisfaciendo sus necesidades presentes sin comprometer a las generaciones futuras, tal como lo definió la Comisión Mundial sobre Medio Ambiente y Desarrollo (1992).

En esta nueva trama que se requiere, es menester la complementariedad de elementos económicos, ambientales, ecológicos, sanitarios, políticos, culturales, territoriales, comunitarios e institucionales, la cual debe apostar por una mayor participación y reciprocidad entre los diversos actores sociales, sustancialmente los residentes del poblado, además de agentes estatales y capitalistas, cruzando las relaciones en una horizontalidad de diálogo en simetría, en democracia, en el respeto por la vida y las manifestaciones culturales de los distintos grupos étnicos del altiplano; implementando, asimismo, las correspondientes mitigaciones en el daño al medio ambiente natural y cultural, particularmente en el 
salar y en los diversos pueblos y aldeas aledaños. A decir de Gallopín (2003), en el horizonte temporal se debe plantear la necesidad de una equidad inter- e intrageneracional.

Podemos indicar que la articulación entre naturaleza, sociedad y capitalismo turístico puede ser posible en un marco llamado socioecológico (Gallopín, 2003), donde el énfasis se sitúe en el bienestar más allá de la acumulación por desposesión (Harvey, 2014), apostando al equilibrio de los sistemas sociales, culturales y ambientales.

Al apelar al desarrollo sustentable, se apela a un proceso de transformación e innovación, a la inauguración de un devenir de armonización, de las ganancias y beneficios para los mismos territorios, para dar fin a la colonialidad y sacrificialidad que hemos expuesto en este trabajo. Para ello, el mejoramiento de las políticas públicas debe situar en el centro al desarrollo comunitario con objeto de resolver las necesidades del presente armonizando la herencia hacia las futuras generaciones. Como señaló Fricker (1998), el desafío de la sustentabilidad no es enteramente técnico ni racional, sino que es uno de cambio en las actitudes y en el comportamiento: "La sustentabilidad entonces debe incluir el discurso social en el que los aspectos fundamentales son explorados colaborativamente dentro de los grupos o comunidades afectadas" (Fricker, 1998, p. 369).

Uyuni, en todo este escenario, se transformó con la hegemonía de las acciones del capitalismo, con sus agentes y redes, otorgando nuevos sentidos a las comunidades regionales que se sentían y se sienten hasta hoy aisladas, presas de la inseguridad, en un contexto de incertidumbre basado en la neocolonialidad económica, política y sociocultural de deterioro (Bauman, 2010).

La vanagloria de "capital turística" de Bolivia se constituyó como eje semántico de la política, la publicidad, el mercadeo visual, recurriendo majaderamente a los indicadores cuantitativos, visibilizando siempre el "crecimiento", a saber que no siempre crecimiento es sinónimo de desarrollo, sino una condición, como dijera Boisier (2010), apostillando a que el desarrollo necesariamente debe considerar el bienestar de la población. Tal como explicara Vázquez Barquero, el desarrollo debe apuntar hacia "los procesos de crecimiento y cambio estructural que persiguen satisfacer las necesidades y demandas de la población y mejorar su nivel de vida” (2007, p. 185). Entre otros elementos, concretamente proponer empleos sustentables, participación comunitaria y disminución de la pobreza. 
Las relaciones asimétricas entre el turismo, el capitalismo, los agentes foráneos, los políticos y la población local dificultaron el diálogo, estableciéndose de ese modo un monólogo hegemónico del capital, quien dictó y transformó el territorio promoviendo o derivando en la pauperización y en la colonialidad hacia la población por parte de los visitantes que, admirados por la belleza del salar, también practicaron la exotización de la pobreza en esa porción del sudoeste boliviano, en la capital del turismo altiplánico.

\section{Fuentes consultadas}

Ardenti, R. y Vrain, P. (1999). Relations interentreprises et rapports de domination. Innovations, Cahiers d'économie de l'innovation, 9, 51-73.

Bauman, Z. (2010). La globalización: consecuencias humanas (trad. de Daniel Zadunaisky). México: Fondo de Cultura Económica.

Becattini, G. (1992). Le district marshallien: une notion socio-économique. En G. Benko y A. Lipietz, Les Régions qui gagnent (pp. 35-55). París: Presses Universitaires de France.

Boisier, S. (2010). Territorio, Estado y sociedad en Chile, la dialéctica de la descentralización: entre la geografía y la gobernabilidad. Santiago de Chile: Mago Editores.

Bunker, S. y Ciccantell, P. S. (2005). Globalization and the Race for Resources. Baltimore: Johns Hopkins University Press.

Castells, M. (2006). La sociedad red. Madrid: Alianza Editorial. Chungara, V. (2011). Tradiciones y leyendas de Uyuni. Uyuni: Autor.

Codespa. (2015). Pueblos mágicos de los Lipez: la oportunidad contra la pobreza en el Salar de Uyuni. Madrid. Recuperado de http://bit.ly/2kRSkCW.

Comisión Mundial sobre Medio Ambiente y Desarrollo. (1992). Nuestro futuro común. Madrid: Alianza Editorial.

Derrida, J. (1997). El monolingüismo del otro, o la prótesis de origen. Buenos Aires: Manantial.

Dirección Municipal de Turismo y Cultura de Uyuni. (2009). Informe anual sobre actividad turística en Uyuni, Bolivia. Uyuni: Autor.

Dube, S. (septiembre-diciembre, 2007). Llegadas y salidas: la antropología histórica. Estudios de Asia y África, XLII(3), 595-645. 
Ferrer, S. (2009). La asimetría en los esquemas de reproducción de Marx. Cuadernos de Economía, XXVIII, 1-15.

Fischer-Kowalski, M. y Haberl, H. (2000). El metabolismo socioeconómico. Ecología Política, 19, 21-35.

Foucault, M. (2008). Seguridad, territorio, población. Madrid: Akal.

Fricker, A. (1998). Measuring up to sustainability. Futures, 30(4), 367-375.

Galaz-Mandakovic, D. (2012). El escenario de la migración en Tocopilla en el devenir del siglo xx. Tres colectivos alóctonos y la fuga autóctona. Revista de Ciencias Sociales, 29, 105-131. Recuperado de http://www. redalyc.org/articulo.oa? $\mathrm{id}=70824863005$

Galaz-Mandakovic, D. (2014). Uyuni, capital turística de Bolivia. Aproximaciones antropológicas a un fenómeno visual posmoderno desbordante. Teoría y Praxis, 16, 147-173. Recuperado de http://www.redalyc. org/articulo.oa?id $=456145102007$

Galaz-Mandakovic, D. (2016). Industrialización minera, urbanización e innovación en las relaciones sociales en el sudoeste del altiplano boliviano: el caso de la Compañía Huanchaca de Bolivia (1834-1930). Estudios Atacameños, 52, 153-175. Recuperado de http://dx.doi.org/10.4067/ s0718-10432016005000001

Gallopín, G. (2003). Sostenibilidad y desarrollo sostenible: un enfoque sistémico (serie Medio Ambiente y Desarrollo 64). Santiago de Chile: Comisión Económica para América Latina y el Caribe.

Harvey, D. (2014). Diecisiete contradicciones y el fin del capitalismo. Quito: Instituto de Altos Estudios Nacionales.

Instituto Prisma. (2015). En la Ruta del Censo (dossier trimestral 37). La Paz, Bolivia: Nueva Crónica.

Lajugie, J. (1987). Los sistemas económicos. Buenos Aires: Eudeba.

Levin, V. (1960). The Export Economies: Their Pattern of Development in Historical Perspective. Cambridge: Harvard University Press.

López Pérez, V. (2011). Uyuni: historia de un pasado glorioso. Cochabamba: Adonai.

Mandel, E. (1976). Tratado de economía marxista. México: Era.

Marx, K. (2004). Manuscritos económico-filosóficos de 1844. Buenos Aires: Colihue. 
Mesa Gisbert, C. D., Mesa, J. de y Gisbert, T. (2007). Historia de Bolivia. La Paz, Bolivia: Gisbert.

Querejazu, R. (1996). Uyuni: ciudad benemérita y ciudad predilecta de Bolivia: sus antecedentes, fundación y sintesis de su historia hasta la Guerra del Chaco. Cochabamba: Poligraf.

Ramos, R. (2012). "Yo no sé que será eso, porque yo no tengo tiempo para eso". Prácticas y discursos sobre el tema transversal equidad de género en Uyuni (Tesis para optar al grado de magíster en Educación Intercultural Bilingüe con la mención Formación Docente). Universidad Mayor de San Simón, Facultad de Humanidades y Ciencias de la Educación, Cochabamba, Bolivia.

Roseberry, W. (2002). Understanding capitalism - Historically, structurally, spatially. En D. Nugent (ed.), Locating Capitalism in Time and Space. Global Restructurings, Politics, and Identity (pp. 61-79). Standford: Standford University Press.

Schumpeter, J. (1942). Capitalism, Socialism and Democracy. Londres: Routledge.

Sklodowska, E. (1992). Testimonio hispanoamericano: historia, teoría, poética. Nueva York: Peter Lang.

Sombart, W. (1984). El apogeo del capitalismo. México: Fondo de Cultura Económica.

Sztulwark, S. (2013). La segmentación productiva en la industria. Evolución de modalidades de valorización y dispersión de actividades en cadenas globales específicas. En C. Yáñez (ed.), Chile y América en su historia económica (pp. 279-292). Valparaíso: Asociación Chilena de Historia Económica.

Vázquez Barquero, A. (2007). Desarrollo endógeno. Teorías y políticas de desarrollo territorial. Investigaciones Regionales, 11, 183-210. Recuperado de http://www.redalyc.org/articulo.oa?id = 28901109

Veizaga, H. (2003). Uyuni, una mirada al pasado. Recuperado de http://uyuniweb.com/antano/pagina.php?sip $=34$

Veltz, P. (1999). Mundialización, ciudades y territorios. Barcelona: Ariel.

Viceministerio de Turismo. (2011). Plan Nacional de Turismo 2012-2016. La Paz: Ediciones del Ministerio de Culturas y Turismo de Bolivia. 
Weber, M. (1998). Economía y sociedad. México: Fondo de Cultura Económica.

Zemelman, H. (2005). Sujeto y sentido: consideraciones sobre la vinculación del sujeto con el conocimiento que construye. En Voluntad de conocer. El sujeto y su pensamiento en el paradigma crítico (pp. 81-94). Barcelona: Anthropos Editorial. 
